\title{
New insight into biology, molecular diagnostics and treatment options of unstable carotid atherosclerotic plaque: a narrative review
}

\author{
Arkadiusz Migdalski^, Arkadiusz Jawien^^ \\ Department of Vascular Surgery and Angiology, L. Rydygier Collegium Medicum in Bydgoszcz, Nicolaus Copernicus University in Torun, Poland \\ Contributions: (I) Conception and design: Both authors; (II) Administrative support: A Jawien; (III) Provision of study materials or patients: Both \\ authors; (IV) Collection and assembly of data: Both authors; (V) Data analysis and interpretation: Both authors; (VI) Manuscript writing: Both \\ authors; (VII) Final approval of manuscript: Both authors. \\ Correspondence to: Arkadiusz Jawien. Department of Vascular Surgery and Angiology, A. Jurasz University Hospital, Maria Curie-Skłodowska St. 9, \\ 85-094 Bydgoszcz, Poland. Email: ajawien@cm.umk.pl.
}

\begin{abstract}
Indications for intervention in hemodynamically relevant carotid artery stenosis (carotid endarterectomy or stenting) are primarily based on a degree of stenosis and symptomatology. To date the plaque vulnerability is rarely taken into account in clinical decision making although development of molecular imaging allows a better understanding of plaque biology and provides new techniques detecting potentially vulnerable plaque at risk. A significant number of reports describing the mechanisms of unstable plaque formation suggest that it is a multifactorial process. Inflammation, lipid accumulation, apoptosis, proteolysis, the thrombotic process and angiogenesis are among the main factors of carotid plaque destabilization. Although inflammation is a key process in development of plaque vulnerability, the hemostasis and neoangiogenesis should be regarded as equally important. Only a small group of asymptomatic patients may benefit from the invasive treatment and it remains a challenge to determine whether initially asymptomatic carotid plaque become unstable or vulnerable. Currently, the main task of research on atherosclerotic lesion imaging is focused on functional state of the plaque. The presence of one or more features such as stenosis progression, large plaque area, large juxta-luminal black area, plaque echolucency, intra-plaque hemorrhage, impaired cerebral vascular reserve and spontaneous embolization may indicate patients at higher risk for stroke suitable for revascularization. Treatment of carotid stenosis as one of the manifestations of generalized atherosclerosis requires a broad approach. Nowadays pharmacological treatment options for the atherosclerotic process are largely aimed at stimulating the plaque stabilization, but in symptomatic patients and selected asymptomatic patients, carotid plaque should be removed as a potential source of embolism.
\end{abstract}

Keywords: Carotid stenosis; vulnerable carotid plaque; carotid plaque destabilization

Submitted Oct 30, 2020. Accepted for publication May 24, 2021.

doi: $10.21037 / \mathrm{atm}-20-7197$

View this article at: http://dx.doi.org/10.21037/atm-20-7197

^ ORCID: Arkadiusz Migdalski, 0000-0002-9835-5103; Arkadiusz Jawien, 0000-0001-8380-9371. 


\section{Introduction}

Symptomatology and degree of carotid artery stenosis are main indications for carotid interventions at the moment. However, two thirds of all patients presenting with major stroke had no previous minor neurological symptoms. Based on the North American Symptomatic Carotid Endarterectomy Trial (NASCET) and the European Carotid Surgery Trial (ECST) reports there is a general agreement that carotid endarterectomy (CEA) in symptomatic stenosis greater than $70 \%$ is followed by significant absolute ischemic stroke risk reduction and should be routinely performed $(1,2)$. On the other hand, most of asymptomatic patients with severe carotid artery stenosis are subject to unnecessary interventions (whether endarterectomy or stenting) taking significant risk of perioperative morbidity or even mortality, while with modern best medical therapy (BMT) the annual risk of stroke in that group of patients is around $0.5 \%$ (3). Only the small group of asymptomatic patients $(\sim 15 \%)$ benefit from the invasive treatment (3).

It remains a challenge to determine if initially asymptomatic carotid atherosclerotic plaque will become unstable or vulnerable. The American Heart Association (AHA) and the American Stroke Association (ASA) invariably recommend that carotid intervention should only be performed in strictly selected patients with asymptomatic carotid stenosis (ACS), but the criteria for the abovementioned selection have not been defined so far (4). Until the results of ongoing trials are published and validated algorithms for patient selection are created, clinicians are using the clinical and imaging criteria suggested by experts from the European Society of Vascular Surgery (ESVS). (5) The presence of one or more features such as silent infarction on computed tomography/magnetic resonance imaging (CT/MRI), stenosis progression, large plaque area, large juxta-luminal black area (JBA) on computerized plaque analysis, plaque echolucency, intra-plaque hemorrhage on MRI, impaired cerebral vascular reserve (CVR), and spontaneous embolization on transcranial Doppler (TCD) monitoring, might indicate patients at higher-risk for stroke suitable for revascularization (5).

It is believed that vulnerable, non-stenotic plaques are an underestimated cause of stroke (6). Currently, the main topics of research on imaging of atherosclerotic lesions are turning towards the functional state of the plaque and the identification of high-risk groups (6). It is well known that stable plaques with a fibrous structure are less susceptible to rupture and related complications than unstable plaques in which an intense inflammatory process takes place (Table 1). These two groups of plaques in typical, routinely performed imaging studies are difficult to distinguish. Currently, there are numerous novel imaging techniques that can detect potentially unstable plaques: magnetic resonance imaging, high-resolution computed tomography, positron emission tomography and contrast-enhanced ultrasound (7-11). Processes indicating plaque activity (molecular imaging) such as: glucose absorption, protein degradation, exposure of adhesive molecules or content of markers for apoptosis are tested for use in the diagnosis of plaques at risk of destabilization (12-15).

We present the following article in accordance with the Narrative Review reporting checklist (available at http:// dx.doi.org/10.21037/atm-20-7197).

\section{Biology}

The trigger of atheroma formation is an endothelial dysfunction followed by inflammatory response to lipoprotein retention predominantly in the arterial wall segments in which the shear stress is decreased and the blood flow is oscillatory and turbulent $(16,17)$. In such parts of arterial wall the prolongend contact with endothelium of blood derived particels [mainly low-density lipoprotein (LDL)] takes place. Such a situation leads to accelerated accumulation of lipoproteins in subendithelial matrix of the arterial wall (18). When macrophages are not able to eliminate exessive amount of lipids, vascular smooth muscle cells (VSMCs) start to be activated and migrate into subendothelial layer. The VSMCs proliferate, change their phenotype into fibroblast-like cells and start to produce extracellular matrix (mainly collagen and proteoglicans). The fibroblast-like VSMCs and connective tissue produced by them are the main components of the plaque's fibrous cap (18). Atherosclerotic plaque instability is mainly associated with the inflammatory process, while plaque stabilization is mediated by smooth muscle cell proliferation and collagen deposition $(19,20)$.

There are numerous inflammatory biomarkers which levels are increased in patients with carotid stenosis and the link between elevated inflammatory markers and atherosclerotic plaque destabilization has also been demonstrated (21). The best validated are: highsensitivity C-reactive protein (hsCRP), interleukins (IL6, IL-1B, IL-8, IL-10), soluble Vascular Cell Adhesion Molecule-1 (sVCAM), osteopontin, serum amyloid A (SAA), 
Table 1 Selected features of stable and unstable carotid atherosclerotic plaque

\begin{tabular}{ll}
\hline Stable plaque & Unstable plaque \\
\hline Thick fibrous cap & Thin fibrous cap \\
Severe calcification & Scarce calcification \\
Macroscopic calcium & Microcalcific deposits within the fibrous cap \\
Small lipid core & Extensive necrotic core, rich in lipids \\
Intensive proliferation of VSMCs & Strongly expressed inflammation, infiltration of macrophages \\
Stable, scarce rebuilding & Proteolysis and continuous rebuilding \\
No intraplaque microhemorrhages & Intensive neovascularization, microhemorrhages \\
High collagen content & Low collagen content \\
No surface ulcerations & Surface ulcerations \\
\hline
\end{tabular}

VSMCs, vascular smooth muscle cells.

lipoprotein-associated phospholipase A2 (Lp-PLA2), tissue inhibitors of matrix proteins (TIMP-1, TIMP-2), soluble CD40-ligand (sCD40L) and matrix metallo-proteinases (MMPs) (21-24). Especially MMP-9, produced by activated macrophages, which is able to destroy the extracellular matrix is believed to be a promising marker of unstable plaque. The connection between histological features of atherosclerotic plaque vulnerability and serum levels of MMPs, TIMP-1 and IL-8 has just been demonstrated (25).

Unstable plaque usually has a thin fibrous cap, lipidrich necrotic core and is characterized by increased activity of inflammatory processes, macrophage infiltration and neovascularization $(26,27)$. In the advanced atherosclerotic plaque, the pivotal mechanism accelerating the plaque growth and frequently leading to local vascular complications and embolization is the fibrous cap rupture (26,27). While macroscopic calcium seems to stabilize atheroma, the microscopic calcium deposits can increase the risk of fibrous cap rupture by amplifying mechanical stress at the level of the fibrous cap (28). The blood inflow into the ruptured plaque cavity is followed by a thrombus formation what trigger the plaque growth acceleration and lead to thrombus propagation into the vessel lumen and its occlusion as a final result $(26,27)$. The main players in the above-mentioned process are thrombotic factors and their inhibitors.

Optional mechanism which can lead to plaque activation and destabilization is the rupture of deficient vessels formed inside the plaque within the neovascularization process. Such a sequence of events provokes intra-plaque hemorrhage without a fibrous cap rupture. It has been demonstrated that symptomatic plaques showed more, larger and more irregular neo-vessels than asymptomatic plaques what is associated with intraplaque hemorrhage (IPH) and secondary plaque rupture (29). The neovascularization process is controlled mainly by vascular endothelial growth factor (VEGF) and its receptors. The plaque homogenates and the plasma of patients with carotid stenosis are characterized by potent prothrombotic profile showing significantly higher concentration and activity of tissue factor (TF) (30). Rupture of the unstable plaque reveals tissue-presenting cells to a stream of flowing blood. In this way, a blood clot forms, which in turn becomes the cause of cardiovascular episodes, including ischemic stroke (30). The main reservoir of TF in the wall of a healthy vessel is the media and VSMCs or fibroblasts located mainly in the adventitia (31). The concentration of TF in plasma increases in many diseases in which intensified inflammation occurs, including atherosclerosis and diabetes (31). A large proportion of TF is found inside the plaque, mainly in macrophages and endothelial cells. Damage to the plaque cap leads to the expression of endothelial cells TF, intraplaque TF and also TF of cells circulating in the blood, enhancing the thrombotic process (32). Undoubtedly, TF plays a key role in the pathogenesis of atherosclerosis and should be taken into account as a potential therapy target for preventing atherothrombotic clots, but also for preventing restenoses after angioplasty and carotid artery stenting. Tutar $e t a l$. showed a correlation of TF concentration with restenoses after angioplasty and coronary artery stenting, most likely through the effect of this factor on stimulation of VSMCs proliferation and migration (33).

The concentration and activity of coagulation inhibitors [tissue factor pathway inhibitor (TFPI); thrombomodulin 
(TM)] is also increased in the advanced carotid plaque (30). TFPI is considered the main natural inhibitor of coagulation activation dependent on the tissue factor. It is believed that associated mainly with the endothelial surface TFPI plays a key role in regulating the function of vascular wall cells and is considered as a marker of endothelial dysfunction (34). Evidence shows that TFPI inhibits the thrombotic process, but it is also supposed that it can play an important role in prevention of restenosis. Macrophages (mainly M2) seem to be a key source of TFPI in developing atherosclerotic plaque. Stavik et al. showed TFPI mRNA values in carotid plaques in patients undergoing endarterectomy twice as high compared to the wall of healthy arteries (35). There is a tendency for higher TFPI levels in symptomatic and unstable carotid plaques with high lipid content (compared to calcified and asymptomatic plaques) (35). However, there are also studies in which there were no statistically significant differences in the concentration and activity of TFPI in symptomatic and asymptomatic plaques $(30,36)$. Most of the reports indicate that TFPI has a protective role, reducing the effects of excessive tissue factor activity. The increased content of TFPI in the vessel wall, especially in the place of a ruptured unstable atherosclerotic plaque, may limit the formation of a thrombus which is the source of thromboembolic complications and slow down the development of atherosclerotic lesions (37).

In advanced atherosclerotic lesions hypoxia, exacerbated inflammation, oxidative stress promoting LDL oxidation leads to the chronic secretion of vascular endothelial growth factor (VEGF) that, in turn, stimulate pathological impaired intraplaque neoangiogenesis (38). It has been demonstrated that VEGF can play a dual role of being an angiogenic and inflammatory cytokine in patients with vulnerable plaque. The analysis of angiogenesis markers shows significantly higher concentration of VEGF in plaques than in plasma of patients with severe carotid stenosis (30). Furthermore, it was proven that concentration of VEGF is increased in symptomatic carotid plaques what confirms its involvement in the carotid plaques neovascularization that can lead to plaques destabilization (30). Mofidi et al. reported that in the carotid atherosclerotic plaques, the content of microvessels formed in the process of neovascularization is positively associated with plaque hemorrhages, its instability and neurological symptoms (39). Red blood cells extravasated during microhemorrhage, undergo hemolysis (into iron, cholesterol, glycophorin A and ceroids), leading to the accumulation of hemoglobin, which through the formation of reactive oxygen species (ROS) leads to increased inflammation and destabilization of the plaque (40).

\section{Molecular imaging}

Molecular imaging techniques of the carotid plaque have been gaining popularity during the last decade. The objective of molecular imaging of the carotid atheroma is to provide biologic insight into the plaque structure and functional status predisposing to vulnerability. Positron emission tomography (PET) with F-18-fluorodeoxyglucose (FDG) is one of the most promising molecular imaging techniques that is able to detect a carotid plaque with an intense inflammatory process due to increased FDG uptake by activated macrophages at the plaque level reflecting the degree of macrophage infiltration (41-43). It has been demonstrated that FDG uptake is higher in patients with symptomatic carotid stenosis and correlate with markers of intraplaque inflammation at the immunobiological analysis $(41,44)$. The FDG uptake is particularly expressed in macrophage-rich areas of the plaque what can be a promising marker of high-risk vulnerable plaque and patients at risk of neurological ischemic events in the near future (44). It has been recently demonstrated that increased FDG uptake into the carotid plaque on PET examination is able to predict future recurrent stroke (45). A positive correlation between the increased inflammatory activity in the atherosclerotic plaque in 18-FDG PET imaging (increased 18-FDG uptake, target to background ratio - TBR) and the concentration of IL- 6 , TNF- $\alpha$ and CRP has been demonstrated $(46,47)$. Another less used type of positron emission tomography procedure with application of F-18 sodium fluoride $\left(\left[{ }^{18} \mathrm{~F}\right] \mathrm{NaF}\right)$ is able to detect microcalcific deposits in the plaque fibrous cap which are responsible for increased mechanical stress leading to a cap rupture (28). $\left[{ }^{18} \mathrm{~F}\right] \mathrm{NaF}$ was originally developed as a hydroxyapatite-seeking agent for the evaluation of bone and joint diseases but secondarily it turned out that it is taken up by active microcalcification characteristic of vulnerable plaque $(28,48-50)$.

Both PET-FDG and PET-NaF appear to be promising diagnostic tools to detect potentially vulnerable carotid plaque but are not widely used because of poor availability and prolonged test time. Molecular images such as PET-CT have the advantage of being sensitive to assessment a degree of inflammation, the most powerful marker of vulnerable carotid plaque, but are unable to assess anatomical signs of vulnerability (intraplaque hemorrhage, cap ulcerations and 
rupture, plaque echolucency and heterogenicity). Hybrid PET/CT and PET/MR are being increasingly used to colocalize inflammation activity signals with anatomical and functional imaging to improve diagnostic precision and evaluate interventions targeted at inflammation and atherosclerosis $(51,52)$. PET-FDG imaging was also used to evaluate the effects of therapy. By intensifying the statin therapy, it was found that inflammation of the vessel wall was reduced, what was shown by reduction of $\left[{ }^{18} \mathrm{~F}\right]$ FDG uptake in the PET images (53). When testing antidiabetic drugs, it was found that pioglitazone, compared to glimepiride, more significantly reduced inflammation of the artery wall in PET-FDG examination (54).

It has been hypothesized that VEGF could become a marker of unstable atherosclerotic plaque. Obviously, the assessment of VEGF expression in tissue is associated with a more invasive approach than just blood collection, but it is already successfully used in cancer diagnosis and therapy, especially in assessing the effects of treatment and cancer invasiveness. An example is the evaluation of tumor tissue activity using labeled (zirconium-89), recombinant monoclonal antibody (bevacizumab) binding to VEGF, imaged by positron emission tomography (89Zrbevacizumab PET) $(55,56)$.

Immunoscintigraphy is another molecular imaging able to detect radioactive tracers that accumulate within vulnerable carotid plaque. Most frequently used tracers are immunoglobulins, antifebrin antibodies, platelets, LDL, hematoporphyrin derivatives and fibronectin.

\section{Treatment options}

The management of carotid stenosis as one of the manifestations of generalized atherosclerosis requires a broad approach. It includes risk factors reduction, lifestyle modification and pharmacological therapy. Symptomatic carotid plaque with high grade stenosis requires surgical treatment (either endarterectomy or stenting) but for most patients with carotid stenosis the therapy focused on plaque stabilization is safer and should be the method of choice. The pathogenesis of atherosclerosis in distinct parts of the vascular bed is slightly different, however, in most cases, the clinical manifestations of atherosclerosis arise not as an effect of the gradual development of atherosclerotic lesions, but as a result of destabilization of the atherosclerotic plaque. Sudden occlusion or embolism associated with destabilization of the plaque is the main cause of cardiovascular episodes (myocardial infarction, ischemic stroke, critical and acute limb ischemia). Hence, therapeutic options for treating the atherosclerotic process are largely geared to stimulating atheroma stabilization and the development of new therapeutic method is highly anticipated.

Nowadays the best treatment slowing down atherosclerotic plaques progression and preventing their destabilization seems to be high-intensity statins therapy. The risk of death from coronary artery disease (CAD) increases fourfold as cholesterol rises from 5.2 to $7.8 \mathrm{mmol} / \mathrm{L}(57)$. The lipid profile predisposing to atheroma formation is increased concentration of lowdensity lipoprotein (LDL), hypertriglyceridemia and reduced level of high-density lipoproteins (HDL). Such a lipemic phenotype is closely related to obesity, insulin resistance, hypertension and disorders of postprandial lipoprotein metabolism. This proves that the therapeutic approach to atheroma stabilization should be broad and multifactorial. The fact that statins have pleiotropic effects, including anti-inflammatory and antioxidant properties, is well-documented $(58,59)$. According to the recent recommendation of ESVS statin therapy is recommended for long-term prevention of stroke, myocardial infarction and other cardiovascular events in all patients with ACS. (5)

The renin angiotensin aldosterone system (RAA) blockade has been reported to slow down the development of atherosclerosis regardless of blood pressure (60). A synergistic effect of hypertension and hypercholesterolemia in the progression of atherosclerotic lesions was observed. Animal studies show that blockade of the RAA system with statins administration inhibits the progression of atherosclerosis to a greater extent than administration of only RAA blockers alone, which is most likely associated with additional inhibition of the inflammatory process by statins (61). Statins can also have a beneficial effect on the elasticity of the arteries (61). Similar studies showing greater efficacy of antihypertensive treatment combined with statins administration, have also been performed in the human population (62). ESVS recommends antihypertensive treatment for all patients with hypertension and ACS to maintain long-term blood pressure $<140 / 90 \mathrm{mmHg}$. (5)

Many reports indicate that extensively used antiplatelet agents (including aspirin), have anti-inflammatory properties conferring a benefit in atherosclerosis management in addition to their other mechanisms of action (63). The anti-inflammatory properties of aspirin are well known. It inhibits cyclo-oxygenase and other proinflammatory signaling pathways, including the nuclear 
Table 2 Selected treatment options to stabilize atheroma

\begin{tabular}{ll}
\hline Currently used & Under research \\
\hline High-intensity statins therapy & Colchicine \\
Renin angiotensin aldosterone system (RAA) blockade & Herbs/spices (ginger, garlic, turmeric, green tea) \\
Antiplatelet drugs (including aspirin) & Monoclonal human antibodies (canakinumab) \\
\hline
\end{tabular}

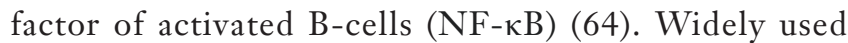
clopidogrel has also anti-inflammatory properties, what has been described in human and animal models $(65,66)$. Lowdose aspirin $(75-325 \mathrm{mg})$ is recommended in all patients with ACS for prevention of late myocardial infarction and other cardiovascular events (5).

Great hopes were raised by research on human monoclonal antibodies. The human monoclonal antibody against IL-6 (toclizumab) and the tumor necrosis factor (TNF) receptor antagonist (etanercept) did not significantly influence the cardiovascular complications of patients with rheumatoid arthritis (67). The monoclonal antibody against IL-1B (canakinumab) remained on the battlefield the only one that turned out to reduce the risk of cardiovascular events (68). Some substances with known anti-inflammatory effects, such as methotrexate (inhibitor IL-6, TNF, CRP), have been proved ineffective in reducing cardiovascular events (69). On the other hand, others, such as colchicine (an anti-inflammatory substance that inhibits the activity of neutrophils) are still under research. The first reports are promising, as colchicine, in addition to high doses of statins, lowers the risk of recurrent cardiovascular episodes $(70,71)$.

Taking into account current medical literature, it seems that the TF can only be recognized as the main regulator of both thrombus formation and atherosclerotic plaque development among all hemostatic factors (30-33). As such, one could await that the TF inhibitor would be of a great value in treating atherosclerosis. Unfortunately, despite promising reports and newly created methods of inhibiting TF, these inhibitors are still not widely used in humans. Research is currently focused on the search for new inhibitors of TF synthesis and targeted anti-TF antibodies. Another possibility is clinical application of recombinant inhibitors of TF, such as recombinant TFPI (72-74). Since the effect of TF is cell-associated and stimulated by a local inflammatory process in the vessel, the hypothesis that TF and its effect can be locally inhibited with no significant effect on systemic coagulation and without a significant increase in bleeding risk, seems very interesting (31).
Many plant compounds and spices are commonly considered to have anti-inflammatory and antioxidant activity (turmeric, ginger, garlic, green tea, chokeberry) however, there are no reliable reports based on randomized clinical trials on their effectiveness in stabilizing atherosclerotic lesions $(63,75,76)$. Selected currently used or investigated treatment options to stabilize atherosclerotic plaque are presented in Table 2.

Due to the improvement in the quality of conservative treatment (best medical therapy, BMT) in the last three decades, there is a noticeable group of clinicians who believe that BMT alone in ACS is sufficient $(77,78)$. However, in addition to reduction of the stroke risk in conservatively well-treated asymptomatic patients, in recent years there was also significant decrease of perioperative stroke during CEA in ACS, up to $0.5 \%$ in selected centers (79). It is clear that the risk of stroke is not the same in all patients with ACS. The structure of a carotid plaque has a key influence on the embolization potential (80). Available data clearly show that ACS patients should not be offered a "one-sizefits-all" approach (80). Moreover, it is often emphasized that a plaque considered as asymptomatic is not always so (symptoms may occur during sleep, cognitive decline) (80-83). Taking into account the current state of knowledge and waiting for further development of pharmacological treatment, it should be stated that in selected asymptomatic patients (high risk of cerebral embolization; low risk of cardiac, pulmonary and other complications; acceptable life expectancy) carotid plaque should be removed as a potential source of emboli $(5,80)$.

\section{Concluding remarks}

Stroke is the second most common cause of mortality and leading reason of adult disability in the present world (84). More than $85 \%$ of strokes are ischemic due to cerebral embolism. An estimate of $20-30 \%$ of all strokes are associated with carotid artery stenosis and it is believed that about $15 \%$ of all strokes and TIAs are caused by unstable carotid plaque (58). The research of factors that are 


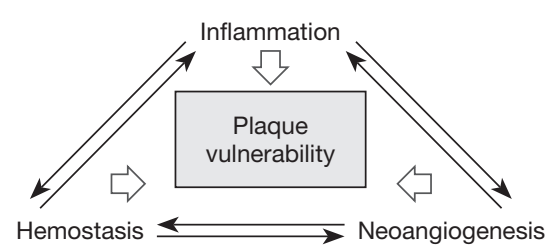

Figure 1 Processes involved in the destabilization of atherosclerotic plaque.

involved in the process of atherosclerotic plaque activation causing it to evolve into an unstable plaque is being carried out extensively. A significant number of reports describing the mechanisms of unstable plaque formation suggest that it is a multifactorial process. In the destabilization of atherosclerotic plaque, the crucial role of inflammation, lipid accumulation, apoptosis, proteolysis, thrombotic process and angiogenesis is indicated. The qualification of symptomatic patients for interventional treatment (CEA or stenting) is beyond doubt. In the case of asymptomatic patients, the decision to undergo surgical treatment is not easy, because it carries the risk of complications, especially neurological ones. At present, it is not possible to indicate which carotid atherosclerotic plaque will become symptomatic and when. Distinguishing plaques that may cause clinical symptoms of stroke in the near future seems to be a key trend in the research. It is proven that patients with ACS greater than $70 \%$ and intraplaque hemorrhage on MRI have nearly 20 -fold higher annual risk of ipsilateral stroke (29.3\% vs. 1.5\%) (85). Such plaques, even asymptomatic, should be considered vulnerable and detected before they lose stability. In the last 20 years there has been a shift in the imaging of the atherosclerotic carotid artery, from the assessment of the degree of luminal stenosis to the characterization of the functional status of the plaque (86). Molecular tests are more promising modality in detecting plaques at the risk of destabilization. To date, none of the plasma biomarkers that would distinguish stable or unstable carotid plaque has entered routine use. Literature data point to the key role not only of the inflammatory process, but also of tissue factor-dependent blood coagulation activation in the formation of atherosclerotic plaque complications $(31,87)$.

Of course, it would be more clinically useful to detect a plasma marker attesting to increased activity of the carotid atherosclerotic plaque. Such a marker, thanks to a simple blood sampling, could be used to identify patients with asymptomatic carotid plaques, which have a greater risk of becoming symptomatic in the near future, causing embolization into the cerebral vessels. Such patients, in addition to conservative treatment (pharmacological treatment and leveling of modifiable risk factors), could be good candidates for a prophylactic CEA.

Despite the fact that the inflammation is a pivotal process in the progression and destabilization of carotid plaque, and most research are conducted in this direction, it must be remembered that the process of hemostasis and neoangiogenesis is equally important (Figure 1.). All three of the above-mentioned processes are interdependent and only understanding their connections brings us closer to understanding the process of atherosclerotic plaque destabilization. Despite numerous studies, at this stage, it cannot be clearly defined which markers of the discussed processes will become crucial in detecting the atherosclerotic plaque at risk of become vulnerable. PETCT is currently the leading molecular test in the diagnosis of unstable carotid plaque, however, focused mainly on the assessment of the inflammation within the plaque. The discovery of new radiotracers (with increased availability, biological sensitivity and more effectively target alternative processes) should change this situation (88). Many of these radiotracers may have been developed and adopted from other domains, such as oncology or neuroimaging.

While awaiting the publication of new reports on unstable carotid plaque markers, we should follow current recommendations and consider all symptomatic, severe stenotic carotid plaques as unstable (5). In asymptomatic patients, we should follow the recommendations and qualify for invasive treatment carefully selected patients with clinical and imaging criteria of plaque instability (5).

\section{Acknowledgments}

Funding: None.

\section{Footnote}

Provenance and Peer Review: This article was commissioned by the Guest Editor (Kosmas I. Paraskevas) for the series "Carotid Artery Stenosis and Stroke - Prevention and Treatment Part II" published in Annals of Translational Medicine. The article has undergone external peer review.

Reporting Checklist: The authors have completed the Narrative Review reporting checklist. Available at http:// dx.doi.org/10.21037/atm-20-7197 
Peer Review File: Available at http://dx.doi.org/10.21037/ atm-20-7197

Conflicts of Interest: Both authors have completed the ICMJE uniform disclosure form (available at http://dx.doi. org/10.21037/atm-20-7197). The series "Carotid Artery Stenosis and Stroke - Prevention and Treatment Part II" was commissioned by the editorial office without any funding or sponsorship. The authors have no other conflicts of interest to declare.

Ethical Statement: The authors are accountable for all aspects of the work in ensuring that questions related to the accuracy or integrity of any part of the work are appropriately investigated and resolved.

Open Access Statement: This is an Open Access article distributed in accordance with the Creative Commons Attribution-NonCommercial-NoDerivs 4.0 International License (CC BY-NC-ND 4.0), which permits the noncommercial replication and distribution of the article with the strict proviso that no changes or edits are made and the original work is properly cited (including links to both the formal publication through the relevant DOI and the license). See: https://creativecommons.org/licenses/by-nc-nd/4.0/.

\section{References}

1. Randomized trial of endarterectomy for recently symptomatic carotid stenosis: final results of the MRC European Carotid Surgery Trial (ECST). Lancet 1998;351:1379-87.

2. Barnett HJ, Taylor DW, Eliasziw M, et al. Benefit of carotid endarterectomy in patients with symptomatic moderate or severe stenosis. North American Symptomatic Carotid Endarterectomy Trial Collaborators. N Engl J Med 1998;339:1415-25.

3. Spence JD. Management of asymptomatic carotid stenosis. Ann Transl Med 2020;8:1262.

4. Meschia JF, Bushnell C, Boden-Albala B, et al. Guidelines for the primary prevention of stroke: a statement for healthcare professionals from the American Heart Association/American Stroke Association. Stroke 2014;45:3754-32.

5. Naylor AR, Ricco JB, de Borst GJ et al. Editor's Choice. Management of Atherosclerotic Carotid and Vertebral Artery Disease: 2017 Clinical Practice Guidelines of the European Society for Vascular Surgery (ESVS). Eur J Vasc
Endovasc Surg 2018;55:3-81.

6. Saba L, Saam T, Jäger HR, et al. Imaging biomarkers of vulnerable carotid plaques for stroke risk prediction and their potential clinical implications. Lancet Neurol 2019;18:559-72.

7. Millon A, Mathevet JL, Boussel L, et al. High-resolution magnetic resonance imaging of carotid atherosclerosis identifies vulnerable carotid plaques. J Vasc Surg 2013;57:1046-51.e2.

8. Grimm JM, Schindler A, Freilinger T, et al. Comparison of symptomatic and asymptomatic atherosclerotic carotid plaques using parallel imaging and $3 \mathrm{~T}$ black-blood in vivo CMR. J Cardiovasc Magn Reson 2013;15:44-63.

9. Yamada K, Kawasaki M, Yoshimura S, et al. High-intensity signal in carotid plaque on routine $3 \mathrm{D}-\mathrm{TOF}-\mathrm{MRA}$ is a risk factor of ischemic stroke. Cerebrovasc Dis 2016;41:13-8.

10. Spanos K, Tzorbatzoglou I, Lazari P, et al. Carotid artery plaque echomorphology and its association with histopathologic characteristics. J Vasc Surg 2018;68:1772-80.

11. Saba L, Francone M, Bassareo PP, et al. CT attenuation analysis of carotid intraplaque hemorrhage. AJNR Am J Neuroradiol 2018;39:131-7.

12. Bitto A, De Caridi G, Polito F, et al. Evidence for markers of hypoxia and apoptosis in explanted human carotid atherosclerotic plaques. J Vasc Surg 2010;52:1015-21.

13. Eslava-Alcon S, Extremera-García MJ, González-Rovira A, et al. Molecular signatures of atherosclerotic plaques: An up-dated panel of protein related markers. J Proteomics 2020;221:103757.

14. Miyazaki T, Miyazaki A. Defective Protein Catabolism in Atherosclerotic Vascular Inflammation. Front Cardiovasc Med 2017;4:79.

15. Tawakol A, Osborne MT, Fayad ZA. Molecular Imaging of Atheroma Deciphering How and When to Use 18F-Sodium Fluoride and 18F-Fluorodeoxyglucose Circ Cardiovasc Imaging 2017;10:e006183.

16. Resnick N, Yahav H, Shay-Salit A, et al. Fluid shear stress and the vascular endothelium: for better and for worse. Prog Biophys Mol Biol 2003;81:177-99.

17. Silver AE, Vita JA. Shear Stress-Mediated Arterial Remodeling in Atherosclerosis. Too Much of a Good Thing? Circulation 2006;113:2787-9.

18. Hansson GK. Inflammation, atherosclerosis, and coronary artery disease. N Engl J Med 2005;352:1685-95.

19. Johnson JL. Matrix metalloproteinases: influence on smooth muscle cells andatherosclerotic plaque stability. Expert Rev Cardiovasc Ther 2007;5:265-82. 
20. Shah PK. Inflammation and plaque vulnerability. Cardiovasc Drugs Ther 2009;23:31-40.

21. Puz P, Lasek-Bal A, Ziaja D, et al. Inflammatory markers in patients with internal carotid artery stenosis. Arch Med Sci 2013;9:254-60.

22. Avgerinos ED, Kadoglou NP, Moulakakis KG, et al. Current role of biomarkers in carotid disease: a systematic review. Int J Stroke 2011;6:337-45.

23. Mayer FJ, Binder CJ, Wagner OF, et al. Combined Effects of Inflammatory Status and Carotid Atherosclerosis. Stroke 2016;47:2952-8.

24. Carbone F, Rigamonti F, Burger F, et al. Serum levels of osteopontin predict major adverse cardiovascular events in patients with severe carotid artery stenosis. Int J Cardiol 2018;255:195-9.

25. Pelisek J, Rudelius M, Zepper P, et al. Multiple biological predictors for vulnerable carotid lesions. Cerebrovasc Dis 2009;28:601-10.

26. Halvorsen B, Otterdal K, Dahl TB, et al. Atherosclerotic plaque stability - what determines the fate of a plaque? Prog Cardiovasc Dis 2008;51:183-94.

27. Finn AV, Nakano M, Narula J, et al. Concept of vulnerable/unstable plaque. Arterioscler Thromb Vasc Biol 2010;30:1282-92.

28. Cocker MS, Spence JD, Hammond R, et al. [18F]-NaF PET/CT Identifies Active Calcification in Carotid Plaque. JACC Cardiovasc Imaging 2017;10:486-8.

29. McCarthy MJ, Loftus IM, Thompson MM, et al. Angiogenesis and the atherosclerotic carotid plaque: an association between symptomatology and plaque morphology. J Vasc Surg 1999;30:261-8.

30. Migdalski A. Aktywacja krzepnięcia zależna od czynnika tkankowego i pobudzenie angiogenezy a stężenie heparanazy u chorych ze zwężeniem tętnic szyjnych. Wydawnictwo Naukowe Uniwersytetu Mikołaja Kopernika. Toruń 2019; ISBN 978-83-231-4159-4:1-181.

31. Holy EW, Tanner FC. Tissue factor in cardiovascular disease pathophysiology and pharmacological intervention. Adv Pharmacol 2010;59:259-92.

32. Steffel J, Luscher TF, Tanner FC. Tissue factor in cardiovascular diseases: molecular mechanisms and clinical implications. Circulation 2006;113:722-31.

33. Tutar E, Ozcan M, Kilickap M, et al. Elevated whole-blood tissue factor procoagulant activity as a marker of restenosis after percutaneous transluminal coronary angioplasty and stent implantation. Circulation 2003;108:1581-4.

34. Kato H. Regulation of functions of vascular wall cells by tissue factor pathway inhibitor. Basic and clinical aspects.
Arterioscler Thromb Vasc Biol 2002;22:539-48.

35. Stavik B, Holm S, Espada S, et al. Increased expression of TFPI in human carotid stenosis. Thromb Res 2017;155:31-7.

36. Migdalski A, Kotschy M, Jawien A. Tissue Factor, Tissue Factor Pathway Inhibitor and Vascular Endothelial Growth Factor-A in Carotid Atherosclerotic Plaques. Eur J Vasc Endovasc Surg 2005;30:41-7.

37. Winckers K, ten Cate H, Hackeng TM. The role of tissue factor pathway inhibitor in atherosclerosis and arterial thrombosis. Blood Rev 2013;27:119-32.

38. Chistiakov DA, Orekhov AN, Bobryshev YV. Contribution of neovascularization and intraplaque haemorrhage to atherosclerotic plaque progression and instability. Acta Physiol (Oxf) 2015;213:539-53.

39. Mofidi R, Crotty TB, McCarthy P, et al. Association between plaque instability, angiogenesis and symptomatic carotid occlusive disease. Br J Surg 2001;88:945-50.

40. Michel JB, Martin-Ventura JL, Nicoletti A, et al. Pathology of human plaque vulnerability: mechanisms and consequences of intraplaque haemorrhages. Atherosclerosis 2014;234:311-9.

41. Rudd JH, Warburton EA, Fryer TD, et al. Imaging atherosclerotic plaque inflammation with [18F]fluorodeoxyglucose positron emission tomography. Circulation 2002;105:2708-11.

42. Vöö S, Kwee RM, Sluimer JC, et al. Imaging Intraplaque Inflammation in Carotid Atherosclerosis With 18F-Fluorocholine Positron Emission TomographyComputed Tomography: Prospective Study on Vulnerable Atheroma with Immunohistochemical Validation. Circ Cardiovasc Imaging 2016;9:e04467.

43. Vesey AT, Jenkins WS, Irkle A, et al. (18)F-Fluoride and (18)F-Fluorodeoxyglucose Positron Emission Tomography After Transient Ischemic Attack or Minor Ischemic Stroke: Case-Control Study. Circ Cardiovasc Imaging 2017;10:e04976.

44. Cocker MS, Spence JD, Hammond R. [18F]fluorodeoxyglucose PET/CT imaging as a marker of carotid plaque inflammation: Comparison to immunohistology and relationship to acuity of events. Int J Cardiol 2018;271:378-86.

45. Kelly PJ, Camps-Renom P, Giannotti N, et al. Carotid Plaque Inflammation Imaged by (18)F-Fluorodeoxyglucose Positron Emission Tomography and Risk of Early Recurrent Stroke. Stroke 2019;50:1766-73.

46. Duivenvoorden R, Mani V, Woodward M, et al. Relationship of serum inflammatory biomarkers with 


\section{Page 10 of 11}

plaque inflammation assessed by FDG PET/CT: the dal-PLAQUE study. JACC Cardiovasc Imaging 2013;6:1087-94.

47. Poredos P, Spirkoska A, Lezaic L, et al. Patients with an Inflamed Atherosclerotic Plaque have Increased Levels of Circulating Inflammatory Markers. J Atheroscler Thromb 2017;24:39-46.

48. Lee H, Lee KS, Lee WW: $18 \mathrm{~F}-\mathrm{NaF}$ PET/CT findings in fibrous dysplasia. Clin Nucl Med 2015;40:912.

49. Lee H, Lee WW, Park SY, et al: F-18 sodium fluoride positron emission tomography/computed tomography for detection of thyroid cancer bone metastasis compared with bone scintigraphy. Korean J Radiol 2016;17:281-8.

50. Joshi NV, Vesey AT, Williams MC, et al: $18 \mathrm{~F}$-fluoride positron emission tomography for identification of ruptured and high-risk coronary atherosclerotic plaques: A prospective clinical trial. Lancet 2014;383:705-13.

51. Joseph P, Tawakol A: Imaging atherosclerosis with positron emission tomography. Eur Heart J 2016;37:2974-80.

52. Raggi P: Atherosclerosis imaging to refine cardiovascular risk assessment in diabetic patients: Computed tomography and positron emission tomography applications.

Atherosclerosis 2018;271:77-83.

53. Tawakol A, Fayad ZA, Mogg R, et al: Intensification of statin therapy results in a rapid reduction in atherosclerotic inflammation: Results of a multicenter fluorodeoxyglucosepositron emission tomography/computed tomography feasibility study. J Am Coll Cardiol 2013;62:909-17.

54. Mizoguchi M, Tahara N, Tahara A, et al: Pioglitazone attenuates atherosclerotic plaque inflammation in patients with impaired glucose tolerance or diabetes. JACC Cardiovasc Imaging 2011;4:1110.

55. Gaykema SB, Brouwers AH, Lub-de Hooge MN, et al. 89Zr-bevacizumab PET imaging in primary breast cancer. J Nucl Med 2013;54:1014-8.

56. van Es SC, Brouwers AH, Mahesh SVK, et al. ZrBevacizumab PET: Potential Early Indicator of Everolimus Efficacy in Patients with Metastatic Renal Cell Carcinoma. J Nucl Med 2017;58:905-10.

57. Marshall WJ, Day A, Lapsley M. Lipids, Lipoproteins and Cardiovascular Disease. Clinical Chemistry 2016, Chapter 17:293-314.

58. Paraskevas KI, Cambria RP. Best Medical Treatment for Patients with Carotid Stenosis: Evidence-Based Medicine or Wishful Thinking? Angiology 2018;69:97-9.

59. Constantinou J, Jayia P, Hamilton G. Best evidence for medical therapy for carotid artery stenosis. J Vasc Surg 2013;58:1129-39.
Migdalski and Jawien. Unstable carotid atherosclerotic plaque

60. Lu H, Cassis LA, Daugherty A. Atherosclerosis and arterial blood pressure in mice. Curr Drug Targets 2007;8:1181-9.

61. Sarkar K, Sinha AK, Mehta JL. The role of statins in endothelial dysfunction in hypertension. Curr Opin Cardiol 2006;21:316-21.

62. Borghi C, Prandin MG, Costa FV, et al. Use of statins and blood pressure control in treated hypertensive patients with hypercholesterolemia. J Cardiovasc Pharmacol 2000;35:549-55.

63. Wijeratne T, Menon R, Sales C, et al. Carotid artery stenosis and inflammatory biomarkers: the role of inflammation-induced immunological responses affecting the vascular systems. Ann Transl Med 2020;8:1276.

64. Morris T, Stables M, Hobbs A, et al. Effects of low-dose aspirin on acute inflammatory responses in humans. J Immunol 2009;183:2089-96.

65. Ayral Y, Rauch U, Goldin-Lang P, et al. Prolonged application of clopidogrel reduces inflammation after percutaneous coronary intervention in the porcine model. Cardiovasc Revasc Med 2007;8:183-8.

66. Patti G, Grieco D, Dicuonzo G, et al. High versus standard clopidogrel maintenance dose after percutaneous coronary intervention and effects on platelet inhibition, endothelial function, and inflammation results of the ARMYDA-150 mg (antiplatelet therapy for reduction of myocardial damage during angioplasty) randomized study. J Am Coll Cardiol 2011;57:771-8.

67. Kim SC, Solomon DH, Rogers JR, et al. Cardiovascular Safety of Tocilizumab Versus Tumor Necrosis Factor Inhibitors in Patients with Rheumatoid Arthritis: A Multi-Database Cohort Study. Arthritis Rheumatol 2017;69:1154-64.

68. Ridker PM, Everett BM, Thuren T, et al. Antiinflammatory Therapy with Canakinumab for Atherosclerotic Disease. N Engl J Med 2017;377:1119-31.

69. Ridker PM, Everett BM, Pradhan A, et al. Low-Dose Methotrexate for the Prevention of Atherosclerotic Events. N Engl J Med 2019;380:752-62.

70. Nidorf SM, Eikelboom JW, Budgeon CA, et al. Lowdose colchicine for secondary prevention of cardiovascular disease. J Am Coll Cardiol 2013;61:404-10.

71. Tardif JC, Kouz S, Waters DD, et al. Efficacy and Safety of Low-Dose Colchicine after Myocardial Infarction. N Engl J Med 2019;381:2497-505.

72. Grover SP, Mackman N. Intrinsic pathway of coagulation and thrombosis. Arterioscler Thromb Vasc Biol 2019;39:331-8.

73. Grover SP, Mackman N. Tissue factor: an essential 
mediator of hemostasis and trigger of thrombosis. Arterioscler Thromb Vasc Biol 2018;38:709-25.

74. Mast AE. Tissue factor pathway inhibitor: multiple anticoagulant activities for a single protein. Arterioscler Thromb Vasc Biol 2016;36:9-14.

75. Tsui PF, Lin CS, Ho LJ, et al. Spices and Atherosclerosis. Nutrients 2018;10:1724.

76. Otunola GA, Oloyede OB, Oladiji AT, et al. Selected spices and their combination modulate hypercholesterolemiainduced oxidative stress in experimental rats. Biol Res 2014;47:5.

77. Abbott AL. Medical (nonsurgical) intervention alone is now best for prevention of stroke associated with asymptomatic severe carotid stenosis: results of a systematic review and analysis. Stroke 2009;40:e573-83.

78. Abbott A. Asymptomatic carotid artery stenosis--it's time to stop operating. Nat Clin Pract Neurol 2008;4:4-5.

79. Vikatmaa P, Mitchell D, Jensen LP, et al. Variation in clinical practice in carotid surgery in nine countries 20052010. Lessons from VASCU-NET and recommendations for the future of national clinical audit. Eur J Vasc Endovasc Surg 2012;44:11-7.

80. Paraskevas KI, Veith FJ, Ricco JB. Best medical treatment alone may not be adequate for all patients with asymptomatic carotid stenosis. J Vasc Surg 2018;68:572-5.

81. Dempsey RJ, Jackson DC, Wilbrand SM, Mitchell CC, Berman SE, Johnson SC, et al. The preservation of cognition 1 year after carotid endarterectomy in patients

Cite this article as: Migdalski A, Jawien A. New insight into biology, molecular diagnostics and treatment options of unstable carotid atherosclerotic plaque: a narrative review. Ann Transl Med 2021;9(14):1207. doi: 10.21037/atm-20-7197 with prior cognitive decline. Neurosurgery 2018;82:322-8.

82. Usman R, Jamil M, Haq IU, Memon AA. Neurocognitive improvement in patients undergoing carotid endarterectomy for atherosclerotic occlusive carotid artery disease. Ann Vasc Dis 2016;9:307-11.

83. Watanabe J, Ogata T, Higashi T, Inoue T. Cognitive change 1 year after CEA or CAS compared with medication. J Stroke Cerebrovasc Dis 2017;26:1297-305.

84. Feigin VL, Nguyen G, Cercy K, et al. The GBD 2016 Lifetime Risk of Stroke Collaborators. Global, Regional, and Country-Specific Lifetime Risks of Stroke, 1990 and 2016. N Engl J Med 2018;379:2429-37.

85. Schindler A, Schinner R, Altaf N, et al. Prediction of Stroke Risk by Detection of Hemorrhage in Carotid Plaques: Meta-Analysis of Individual Patient Data. JACC Cardiovasc Imaging 2020;13:395-406.

86. Saba L, Yuan C, Hatsukami TS, et al. Carotid Artery Wall Imaging: Perspective and Guidelines from the ASNR Vessel Wall Imaging Study Group and Expert Consensus Recommendations of the American Society of Neuroradiology. Am J Neuroradiol 2018;39:E9-31.

87. Jude B, Zawadzki C, Susen S, et al. Relevance of tissue factor in cardiovascular disease. Arch Mal Coeur Vaiss 2005;98:667-71.

88. Farber G, Boczar KE, Wiefels CC, et al. The Future of Cardiac Molecular Imaging. Semin Nucl Med 2020;50:367-85. 